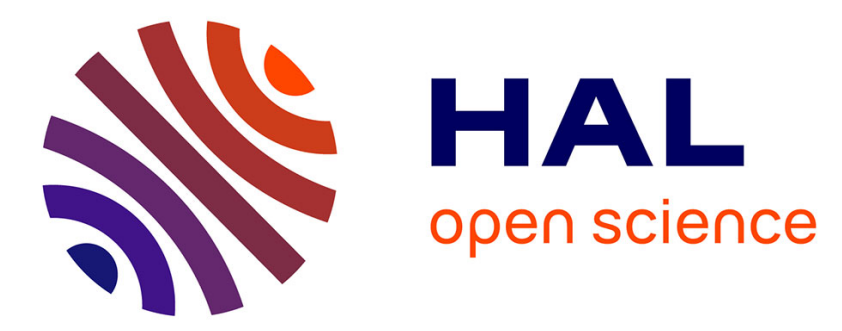

\title{
Replication efficiency of rolling-circle replicon-based plasmids derived from porcine circovirus 2 in eukaryotic cells.
}

Florence Faurez, Daniel Dory, Aurélie Henry, Stéphanie Bougeard, André Jestin

\section{To cite this version:}

Florence Faurez, Daniel Dory, Aurélie Henry, Stéphanie Bougeard, André Jestin. Replication efficiency of rolling-circle replicon-based plasmids derived from porcine circovirus 2 in eukaryotic cells.. Journal of Virological Methods, 2010, 165 (1), pp.27-35. 10.1016/j.jviromet.2009.12.013 . hal-00493407

\section{HAL Id: hal-00493407 https://hal-anses.archives-ouvertes.fr/hal-00493407}

Submitted on 18 Jun 2010

HAL is a multi-disciplinary open access archive for the deposit and dissemination of scientific research documents, whether they are published or not. The documents may come from teaching and research institutions in France or abroad, or from public or private research centers.
L'archive ouverte pluridisciplinaire HAL, est destinée au dépôt et à la diffusion de documents scientifiques de niveau recherche, publiés ou non, émanant des établissements d'enseignement et de recherche français ou étrangers, des laboratoires publics ou privés. 


\section{Replication efficiency of rolling-circle replicon-based}

\section{cells}

Florence Faurez $^{\mathrm{a}}$, Daniel Dory ${ }^{\mathrm{a}^{*}}$, Aurélie Henry ${ }^{\mathrm{a}}$, Stéphanie Bougeard $^{\mathrm{b}}$, André Jestin ${ }^{\mathrm{a}}$

9

${ }^{a}$ French Food Safety Agency (AFSSA), Viral Genetics and Biosafety Unit, F-22440, Ploufragan, France Production Research Unit, F-22440, Ploufragan, France

14

*Corresponding author: Daniel Dory, PhD, AFSSA (French Food Safety Agency), Viral

18 Genetics and Biosafety Unit, BP-53, F-22440, Ploufragan, France

19 Phone: +33296016442

Fax: +33296016283

21 Email: d.dory@afssa.fr 


\section{Replication efficiency of rolling-circle replicon-based plasmids derived from porcine}

\section{circovirus 2 in eukaryotic cells}

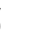

\section{Abstract}

In this study, a method was developed to measure replication rates of rolling-circle repliconbased plasmids in eukaryotic cells. This method is based on the discriminative quantitation of MboI-resistant, non-replicated input plasmids and DpnI-resistant, replicated plasmids. To do so, porcine circovirus type 2 (PCV2) replicon-based plasmids were constructed. These plasmids contained the PCV2 origin of replication, the PCV2 Rep promoter and the PCV2 Rep gene. The results show that the replication rate depends on the length of the PCV2 replicon-based plasmid and not on the respective position of the Rep promoter and the promoter of the gene of interest that encodes the enhanced green fluorescent protein (eGFP). In all cases, it was necessary to add the Rep gene encoded by a plasmid and cotransfected as a replication booster. This method can evaluate the replication potential of replicon-based plasmids quickly and is thereby a promising tool for the development of plasmids for vaccine purposes.

Keywords

1 Porcine Circovirus type 2 (PCV2); rolling-circle; replicon-based plasmid; quantitative PCR 2 assay; replication efficiency. 


\section{Introduction}

Replicon-based plasmids derived from Herpesviruses (e.g. Epstein-Barr virus), Polyomaviruses (e.g. BK virus, Simian virus 40), Papillomaviruses (e.g. bovine papilloma virus 1), or Geminiviruses (e.g. bean yellow dwarf virus) have been developed recently for gene expression and gene therapy (Kim et al., 2006; Mor et al., 2003; Shibata et al., 2005; Van Craenenbroeck et al., 2000b). These plasmids contain a viral origin of replication and the viral genes necessary for replication. Replicon-based plasmids have proved to be highly valuable tools for: (1) producing high levels of proteins of interest in plants (Hefferon and Fan, 2004; Mor et al., 2003); (2) delivering of therapeutic or complementing gene products (Kim et al., 2006); (3) studying the regulation of replication (Takeda et al., 2005); and (4), potentially, enhancing immune responses induced by DNA-based vaccines.

The porcine circovirus type 2 (PCV2), a member of the genus Circovirus, family Circoviridae, contains a circular, single-stranded, positive-sense DNA genome which is about $1.8 \mathrm{~kb}$ in size. The intergenic region containing the origin of replication has a stem-loop structure, which includes an octanucleotide sequence flanked by palindromes, and is bordered by two open reading frames, ORF1 and ORF2. ORF1 is located on the positive strand and encodes the Rep and Rep' proteins involved in replication initiation. ORF2 is located on the negative strand of the intermediate double-stranded PCV2 genome that forms during replication and it encodes the Cap protein, the capsid protein in PCV2 (Mankertz et al., 2004). Owing to their ability to produce high levels of proteins in a short time, PCV2-based plasmids may be valuable vectors for vaccine purposes compared to latent virus-based plasmids. DNA replication of replicon-based plasmids in eukaryotic cells can be measured. The replicated plasmid molecules can be distinguished from the initially transfected, input plasmid molecules by their resistance to the $D p n I$ restriction enzyme, which can only cleave DNA that has been dam-methylated in bacteria. Thus, replicated plasmids can be detected by Southern 

model.

blotting (Mankertz et al., 1997) or by quantitative PCR (qPCR) (Baxter and McBride, 2005; Taylor and Morgan, 2003). In comparison with Southern blotting, quantitative PCR is a highly sensitive and quantitative method for detecting DNA replication and is significantly faster (Taylor and Morgan, 2003).

For DNA-vaccine purposes, it is important to use a replicon-based plasmid - a so-called replicative plasmid — that replicates rapidly to produce high quantities of vaccinating proteins in a short time. However, little is known about the replication efficiency of replicative plasmids. Replication efficiency can be estimated by comparing replicated plasmids to the total number of extracted plasmids. In plasmids that undergo theta replication, replication efficiency has been measured by comparing the number of plasmids after incubation with and without DpnI (Takeda et al., 2005).

The difference between rolling-circle replication and theta replication is that rolling-circle replicons replicate via a nicked-DNA intermediate and produce single-stranded DNA (Faurez et al., 2009). The aim of the present study was to characterise a method to estimate the efficiency of DNA replication of different rolling-circle, replicon-based plasmids using qPCR. This information will be used to determine the replication rates of replicating plasmids and to evaluate whether different primer pairs or different quantitative PCR protocols influence the estimation of replication rates. PCV2 replicon-based plasmids were used as the rolling-circle 


\section{Materials and methods}

\subsection{Culture of PK15 cells}

Porcine circovirus type 1 (PCV1)-free porcine kidney (PK15) cells were grown in Eagle minimal essential medium supplemented with $5 \%$ foetal bovine serum and $1 \%$ penicillin (10 $000 \mathrm{u} / \mathrm{mL})$-streptomycin $(10000 \mu \mathrm{g} / \mathrm{mL})$ (Gibco, Invitrogen, Carlsbad, CA, USA) in 5\% $\mathrm{CO}_{2}$ at $37^{\circ} \mathrm{C}$ and split $1: 10$ twice a week.

\subsection{Replicative and non-replicative plasmid constructs}

The pcDNA3 plasmid and the cloning vectors pCR4 and pBlueScript KS+ were obtained from Invitrogen (Carlsbad, CA, USA). Five fragments were inserted into the plasmids (Figure 1a): (1) the enhanced green fluorescent protein (eGFP) reporter gene (GenBank accession no. U57609.1); (2) the porcine circovirus type 2 (PCV2) OriRep fragment (GenBank accession no. $\underline{\text { AF201311) }}$ that contains the Rep promoter, the origin of replication and ORF1 (Fig. 2); (3) the cytomegalovirus immediate-early promoter (pCMV) of pcDNA3; (4) a PCR amplicon obtained with oGVB2115 primers (Table 1) that contains a $1.3 \mathrm{~kb}$ fragment of the pBlueScript KS+ vector flanked by a KpnI site; (5) a PCR amplicon from pcDNA3obtained with oGVB2117 primers (Table 1) that contains the beginning of the neomycin gene flanked by $X m a \mathrm{I}$ and $M l u \mathrm{I}$ sites.

In all, eleven plasmids were constructed for specific purposes (Fig. 1a). Two plasmids were constructed to optimise the determination of the replication rate. A non-replicative plasmid was obtained by inserting the pCMV and the eGFP reporter gene into pCR4 (pCR4-GFP). A replicative plasmid was obtained by inserting PCV2 OriRep. The PCV2 OriRep fragment was amplified by PCR from PCV2 (Fenaux et al., 2002) using the oGVB2100 primer pair (Table 1) and inserted into pCR4 (pCR4-Orirep). Then, to test the optimised determination method, one non-replicative plasmid and three replicative plasmids were constructed. The non- 
114 replicative plasmid was obtained by inserting the eGFP gene into pcDNA3 (pcDNA3-GFP).

115 For the replicative plasmids, the OriRep fragment was inserted at three different distances

116 from the CMV promoter in the pcDNA3 plasmid. The PCV2 OriRep fragment was amplified

117 by PCR from PCV2 using the oGVB2101 or the oGVB2106 primer pair (Table 1) and

118 inserted into pCR4. Each OriRep fragment was isolated from the pCR4 backbone by digestion

119 with specific restriction endonucleases, as indicated in Figure 1a, and inserted into the

120 pcDNA3-eGFP plasmid at $0.2 \mathrm{~kb}$ (pOrirep0.2-GFP), $1.2 \mathrm{~kb}$ (pOrirep1.2-GFP) or 3.2kb

121 (pOrirep3.2-GFP) from the CMV promoter. To study the influence of the promoter and

122 plasmid size on replication, five additional plasmids were constructed. Three of them were

123 derived from deletions within the replicative plasmid pOrirep0.2-GFP: deletion of the SpeI-

124 pCMV fragment (Fig. 1a pOrirep0.2-GFP CMV'); deletion of the PsiI-pSV40 neomycin

125 fragment (Fig. 1a pOrirep0.2-GFP SV40-); deletion of the SpeI-pCMV fragment and the Psil-

126 pSV40 neomycin fragment (Fig. 1a pOrirep0.2-GFP CMV ${ }^{\top} / \mathrm{SV}^{2} 40^{-5} 5.2 \mathrm{~kb}$ ). The latter plasmid,

127 which contained neither CMV nor SV40 promoters, was used to construct a plasmid with a

128 PCR amplicon obtained using oGVB2115 primers on pBluescript KS+ (pOrirep0.2-GFP

$129 \mathrm{CMV}^{-} / \mathrm{SV} 40^{-} 6.5 \mathrm{~kb}$ ). The fifth plasmid was a pBluescript KS+ plasmid with an EcoRI-OriRep

130 fragment from pCR4-Orirep, a SpeI-pCMV fragment from pcDNA3-GFP and a PCR

131 amplicon obtained using oGVB2117 primers on pcDNA3-GFP and cloned into the open

132 reading frame of pCMV (pKSOrirepCMVNeo) (Table 1).

133 Escherichia coli DH5 $\alpha$ strain was transformed with each of the eleven plasmids. Plasmids

134 were purified using the NucleoSpin® plasmid kit (Macherey-Nagel, Düren, Germany)

135 according to the manufacturer's instructions and sequenced. 
A pcDNA3.1 plasmid encoding the PCV2 ORF1 (Rep) called pcDNA3.1-Rep (Fig. 1b),

139 previously described and characterised in the AFSSA laboratory (Blanchard et al., 2003) was

140 used as a replication booster for the replicative plasmids. Replication of the PCV2 genome is

141 aborted if the tyrosine-96 of motif III of the Rep protein is substituted with phenylalanine-96.

142 However, the mutated Rep protein can still down-regulate the Rep promoter (Mankertz and

143 Hillenbrand, 2002; Steinfeldt et al., 2007). The mutation in motif III of the Rep protein was

144 introduced with the QuikChange XL site-directed mutagenesis kit (Stratagene-Agilent

145 Technologies, Waldbronn, Germany) according to the manufacturer's protocol using

146 pcDNA3.1-Rep as the template. The oGVB2112 primers used for mutagenesis are given in

147 Table 1 . The mutation of the tyrosine-96 in the motif III sequence inhibits the digestion of

148 DNA by PstI. The constructs were thus characterised by enzymatic restriction with PstI and

149 constructs, which could not be digested by this enzyme, were sequenced to confirm the

150 sequence of Rep.

\subsection{Transfection of PK15 cells with PCV2-based replicative and non-replicative plasmids}

154 Twenty-four hours before transfection, $4.5 \times 10^{5}$ of PK15 cells were plated onto 6-well tissue

155 culture plates. The final volume was $2 \mathrm{~mL}$. For the quantitative real-time PCR-based

156 replication assay, $10 \mathrm{ng}$ of plasmids were transfected to optimise the method and $10^{9}$ copies of

157 plasmids were transfected to study the replication of different plasmids. The plasmids were

158 cotransfected with $1 \mu \mathrm{g}$ of pcDNA3.1-Rep or pcDNA3.1-Rep mutated and, for reverse-

159 transcription PCR (RT-PCR), $1 \mu \mathrm{g}$ of plasmids were transfected with Lipofectamine ${ }^{\mathrm{TM}} 2000$

160 (Invitrogen, Carlsbad, CA, USA) according to the manufacturer's instructions. 
163 Twenty-four hours after transfection the cells were scraped into $200 \mu \mathrm{L}$ of PBS $1 \mathrm{X}$ and lysed

164 in protease and the lysis buffer provided with the QIAamp MinElute Virus Spin Kit

165 (QIAGEN, Valencia, CA, USA) for $1 \mathrm{~h}$ at $56^{\circ} \mathrm{C}$. Low-molecular-weight DNA was extracted

166 with the QIAamp MinElute Virus Spin kit (QIAGEN, Valencia, CA, USA) according to the

167 manufacturer's instructions. This kit was used because it has been described as being suitable

168 for purifying single-stranded DNA (Ng et al., 2009). The DNA was resuspended in $100 \mu \mathrm{L}$ of

$169 \mathrm{H}_{2} \mathrm{O}$. Plasmid extractions were performed under a DNA hood (Biocap ${ }^{\mathrm{TM}}$ DNA, Captair ${ }^{\circledR}$ bio,

170 Erlab Biocapt).

171

\subsection{Quantitative real-time PCR-based replication assay}

173 The quantitative real-time PCR-based replication assay was based on the methylation status of

174 plasmids transfected into eukaryotic cells. Methylation status depends on whether or not

175 replication has occurred within eukaryotic cells. Dam-methylation of the GATC site occurs in

176 input plasmids (i.e. generated in prokaryotic (bacterial) cells), whereas the GATC site is not

177 methylated in plasmids that replicate in eukaryotic cells. Therefore, to differentiate replicated

178 from non-replicated plasmids, low-molecular-weight DNA extracted from PK15 cells was

179 incubated either with DpnI that cuts the dam-methylated GATC site or with MboI that, on the

180 contrary, cuts the non-methylated GATC site. To reduce the background level that is observed

181 in quantitative real-time PCR due to incompletely digested DNA, Exonuclease III (ExoIII)

182 was added to digest any incompletely cut DNA (Taylor and Morgan, 2003). ExoIII is an

183 exodeoxyribonuclease that does not act on intact circular plasmids, but rather digests one

184 strand of duplex DNA at a blunt end, at a 5' overhang or at internal nicks. The enzyme acts in

185 a 3' $\rightarrow$ 5' direction and produces stretches of single-stranded DNA (Rogers and Weiss, 1980; 
186 Weiss, 1976). The conditions of digestion used were those described previously (Morgan and

187 Taylor, 2005).

188 In preliminary experiments, TaqMan and SYBR Green real-time PCR assays were compared.

189 The SYBR Green protocol was used in for the rest of the study. Primer pairs and probes

190 indicated in Table 1 were designed using Primer Express ${ }^{\mathrm{TM}}$ Software (Applied Biosystems,

191 Foster City, USA). Quantitative PCR was performed in an ABI Prism 7000 SDS (Applied

192 Biosystems, Foster City, USA) in a $25 \mu \mathrm{L}$ total volume containing 1 X Universal Master Mix

193 or 1 X SYBR Green Master Mix (Applied Biosystems, Foster City, USA), 300 nM each

194 primer, $200 \mathrm{nM}$ probe for the TaqMan protocol and $2 \mu \mathrm{L}$ of digested DNA. After 2 min at

$19550^{\circ} \mathrm{C}$ and incubation for $10 \mathrm{~min}$ at $94^{\circ} \mathrm{C}, 40$ PCR cycles consisting of a $15 \mathrm{sec}$ denaturing step

196 at $94^{\circ} \mathrm{C}$ and a 1 min annealing/extension step at $60^{\circ} \mathrm{C}$ were performed. Plasmid copy numbers

197 were determined by analysing a standard DNA curve ranging from $10^{8}$ to $10^{1}$ plasmid copies.

198 The PCR experiments were performed twice using nine replicates for statistical analysis or

199 twice in duplicate in the rest of the study. Data were analysed using Sequence Detection

200 Software version 1.2.3 (Applied Biosystems, Foster City, USA).

201

2.7 RNA extraction and reverse-transcription PCR

203 Twenty-four hours after transfection, total RNA was extracted from PK15 cells using the

204 TRIzol® reagent according to the manufacturer's instructions (Invitrogen, Carlsbad, CA,

205 USA). Plasmids were present in the same phase as RNA. To eliminate plasmids, $5 \mu$ L of total

206 RNA was incubated with RNase-free DNase as indicated by the manufacturer (QIAGEN,

207 Valencia, CA, USA). Then, $15 \mu \mathrm{L}$ of DNA-free RNA was reverse-transcribed to cDNA with

208 random primers using the high-capacity cDNA archive kit according to the manufacturer's

209 instructions (Applied Biosystems, Foster City, USA). The cDNA was used immediately or

210 stored at $-20^{\circ} \mathrm{C}$ until use. To differentiate Rep RNA from Rep' RNA, intron-flanking primers 
were used (Table 1: 98_F and oGVB2118_R). The amplicon size was 774pb and 391pb for

212 Rep cDNA and Rep' cDNA, respectively. $\beta$-actin cDNA was used as an internal control. The

213 PCR reaction was performed in a total volume of $50 \mu \mathrm{L}$ containing $10 \mu \mathrm{L}$ of cDNA, $10 \mu \mathrm{L}$ of

214 5X Green GoTaq buffer, $0.2 \mu \mathrm{M}$ 98_F and oGVB2118_R primers, $0.2 \mu \mathrm{M}$ each dNTP and 1

215 unit of GoTaq ${ }^{\circledR}$ Flexi DNA polymerase (Promega, Southampton, UK) using the G-STORM

216 GS1 system (Genetic Research Instrumentation, Braintree, Essex, UK). Thermal cycle

217 conditions were as follows: $94^{\circ} \mathrm{C}$ for $5 \mathrm{~min}$ followed by 30 cycles at $94^{\circ} \mathrm{C}$ for $30 \mathrm{sec}, 59^{\circ} \mathrm{C}$ for

$21830 \mathrm{sec}, 72^{\circ} \mathrm{C}$ for $1 \mathrm{~min}$ with a final extension of $72^{\circ} \mathrm{C}$ for $10 \mathrm{~min}$. Amplicons were visualised

219 by $2 \%$ agarose gel electrophoresis and ethidium bromide staining.

\subsection{Statistics}

222 The aim of the statistical analysis was to test in each population, i.e. non-replicative and 223 replicative plasmids, the difference between the quantity of DNA incubated with ExoIII only 224 (qE) and the sum of the quantity of DNA incubated with DpnI and ExoIII (qDE) and MboI and ExoIII (qME). Two-tailed Student $t$-tests were used and computed using Systat 9.0

226 software. The associated power of the Student $t$-tests was computed with the POWER 227 procedure of SAS software (SAS, 2004). The quantities of plasmids in digested DNA samples 228 were considered to be different if the Type I error was less than 5\% and considered to be 229 similar if the Type II error was less than $20 \%$, i.e. a power higher greater than $80 \%$, for an 230 associated Type I error at 5\% (Jenny, 2001; Melot, 2003). The Mann-Whitney test was used 231 for comparisons of differences in the results of real-time PCR on two different amplification 232 targets and in the results of real-time PCR using the TaqMan probe or SYBR Green. 


\subsection{Optimisation of the replication rate calculation}

235 In this study, the replication rate was defined as the percentage of replicated plasmids at $24 \mathrm{~h}$ 236 post-transfection. To evaluate the replication rate of plasmids, a quantitative real-time PCR237 based assay was developed to quantify input plasmids or replicated plasmids, but not the 238 cotransfected pcDNA3.1-Rep replication booster. To do so, the PCR primers targeted a 239 GATC site and this site is not present in pcDNA3.1-Rep. In theory, the quantity of plasmids 240 after incubation with ExoIII (qE) should be equal to the sum of the quantity of plasmids 241 incubated with DpnI and ExoIII and the quantity of plasmids incubated with MboI and ExoIII 242 (qDE+qME). Consequently, the replication rate can be calculated using $\mathrm{qE}$ or $\mathrm{qDE}+\mathrm{qME}$ as 243 the denominator.

244 To test this assumption, the number of plasmid copies of pCR4-GFP and of pCR4-Orirep 245 were quantified. Visually, qE did not appear different from qDE+qME (Fig. 3). In the case of 246 pCR4-GFP, statistics showed that qE and qDE+qME were not significantly different 247 ( $\mathrm{p}=0.766)$. However, these two groups were not shown to be similar, because the Type II 248 error was greater than $20 \%$. To conclude on similarity at a Type II error of $20 \%$, quantitative 249 PCR must be performed 1526 times for each type of plasmid. In the case of pCR4-Orirep, 250 statistical tests showed that $\mathrm{qE}$ and $\mathrm{qDE}+\mathrm{qME}$ were significantly different $(\mathrm{p}=0.017)$.

251 Therefore, the assumption could not be validated for replicative plasmids. The replication rate 252 of replicative plasmids incubated with $\mathrm{MboI}$ and ExoIII exceeded $100 \%$ when using $\mathrm{qE}$ as the 253 denominator in the calculation (data not shown). qME and qDE had the same conditions of 254 digestion; thus the replication rate was calculated using $\mathrm{qDE} /(\mathrm{qME}+\mathrm{qDE})$. 
Reverse-transcription PCR was used to analyse the transcription of Rep and Rep' proteins encoded by pOrirep0.2-GFP or by pcDNA3.1-Rep. Reverse-transcription PCR amplified two cDNA fragments corresponding to the Rep mRNA (774pb) and to the spliced mRNA of Rep' (391pb) for pOrirep0.2-GFP and for pcDNA3.1-Rep (Fig. 4). These bands were not present in the cDNA controls of PK15 cells that were not transfected or that were transfected by nonreplicative pcDNA3. Thus, the expression of both Rep and Rep' could be detected.

\subsection{Necessity of cotransfection with pcDNA3.1-Rep to show the replication rate in vitro}

In preliminary experiments pCR4-GFP or pCR4-Orirep were transfected in PK15 cells

without the replication booster pcDNA3.1-Rep. The mean replication rate of pCR4-Orirep

was similar to that of pCR4-GFP (data not shown). The cotransfection of pcDNA3.1-Rep

resulted in a replication rate of $49 \%$ for pCR4-Orirep (Fig. 5). If the Rep gene of pcDNA3.1-

Rep was mutated, the replication rate of pCR4-Orirep returned to the background level. No replication was observed for pCR4-GFP, even in the presence of pcDNA3.1-Rep.

\subsection{Replication rates determined with two different quantitative real-time PCR methods and for two different amplification targets}

Plasmid replication rates were compared for two primer pairs associated with a TaqMan probe or with the SYBR Green dye. The quantitative real-time PCR-based replication assays were tested with pcDNA3-GFP and pOrirep0.2-GFP (Fig. 1a); each plasmid was cotransfected with pcDNA3.1-Rep. One primer pair was situated in the neomycin gene with a GATC site located in the middle of the amplicon, and the other primer pair was placed at the junction of the GFP gene and the pcDNA3 backbone with a GATC site located in the reverse primer (Fig. 6a).

281 Neither the quantity of plasmids evaluated by the formula qDE+qME (Fig. 6b) nor the 
replication rates (Fig. 6c) were significantly different, whatever the primer pair. This was verified for pcDNA3-GFP and pOrirep0.2-GFP (Fig. 6b and 6c). Moreover, the use of a TaqMan probe or a SYBR Green dye (Fig. 7a) did not introduce significant variation in the quantity of plasmids measured (Fig. 7b) or in the mean replication rates (Fig. 7c) of either construct.

\subsection{Example application: mean replication rate of PCV2-based replicons in PK15 cells 24 h post-transfection}

PCV2-based replicons were cotransfected with pcDNA3.1-Rep into PK15 cells. The nonreplicative plasmids have a mean background replication rate below 5\% (Fig. 8). pCR4Orirep showed a mean replication rate of $63 \% \pm 8 \%$. The mean replication rates of the three replicative plasmids encoding the eGFP gene were lower, i.e. $14 \% \pm 2 \%, 13 \% \pm 3 \%$ and $12 \%$ $\pm 2 \%$ for pOrirep1.2-GFP, pOrirep0.2-GFP and pOrirep3.2-GFP, respectively. Compared to the three replicative eGFP encoding plasmids, pCR4-Orirep was smaller (5.2kb vs. $7.4 \mathrm{~kb})$ and did not contain strong eukaryotic promoters such as pCMV and pSV40.

\subsection{Mean replication rate depended on plasmid size, but not on the presence of strong eukaryotic promoters}

To determine whether the size of the plasmid or the presence of strong eukaryotic promoters could modify the mean replication rates of the PCV2-based replicons, five additional plasmids were constructed and tested. Plasmids with or without eukaryotic promoters and greater than $5.9 \mathrm{~kb}$ in size still had low mean replication rates. On the contrary, $5.2 \mathrm{~kb}$ plasmids with or without eukaryotic promoters had replication rates of about the same magnitude as pCR4Orirep (Fig. 8). 


\section{Discussion}

307 In this study, a rapid, quantitative real-time PCR-based assay was developed to measure the replication rates of PCV2-based replicons. The replication rate was defined as the percentage at $24 \mathrm{~h}$ post-transfection of the number of replicated plasmids compared to the total number of 310 plasmids present in the cells (i.e. replicated and initial input plasmids). The choice of the 311 Escherichia coli strain in which replicon-based plasmids were produced was important. For example, the E. coli TOP10 strain has more mutations in the system of methylation and restriction (hsdRMS gene) than the DH5 $\alpha$ strain; this difference caused an increase in the replication rate (data not shown). Primers for short PCR amplicons containing a GATC sequence were designed to discriminate between replicated and non-replicated plasmids after

316 incubation in eukaryotic cells. A plasmid encoding the PCV2 Rep protein (pcDNA3.1-Rep) 317 was needed to boost and to detect the in vitro replication of the PCV2-based replicons.

318 Comparable replication rates were determined using two different amplification targets. The 319 use of a specific TaqMan probe and amplicon detection using SYBR Green dye also resulted 320 in comparable replication rates.

321 As in theta replication, rolling-circle replication is a semi-conservative replication system.

322 However, a rolling-circle replicon replicates via a nicked DNA intermediate and produce 323 single-stranded DNA (Faurez et al., 2009). The present study showed that the quantity of 324 plasmids after incubation with ExoIII (qE) and the sum of the quantity of plasmids after incubation with $D p n I$ and ExoIII plus the quantity of plasmids after incubation with $M b o$ I and 326 ExoIII (qDE+qME) were significantly different in replicative plasmids. This difference may 327 be due to the products of rolling-circle replication, namely single-stranded DNA and nicked DNA. In contrast to viruses that replicate via rolling-circle replication, rolling-circle replicon329 based plasmids do not encode the capsid protein which up-regulates the amount of single330 stranded DNA by protecting viral DNA from host proteins (Padidam et al., 1999). 
331 Consequently single-stranded DNA probably did not contribute to the difference between qE

332 and qDE+qME. On the contrary, nicked plasmids may have an impact on the number of

333 plasmid copies detected by quantitative real-time PCR. The efficiency of ExoIII digestion

334 may vary with the quantity of nicked DNA and digested DNA (Hoheisel, 1993). The qME to

335 qE ratio exceeded 100\%: more DNA was detected when DNA was incubated with $M b o$ I and

336 ExoIII than with ExoIII only. The difference in the quantity of plasmids detected by

337 quantitative real-time PCR may be due to the complete digestion of nicked DNA in qE but not

338 in qME. ExoIII may digest all the double-stranded plasmids and produce single-stranded

339 DNA, thereby decreasing the number of plasmid copies detected by quantitative real-time

340 PCR. Because qDE and qME had the same conditions of digestion, qDE+qME was used to

341 calculate the replication rate instead of qE. Hemi-methylated plasmids are cleaved by $D p n I$

342 under conditions of enzyme excess, long digestion times or small quantities of DNA template

343 (Lu et al., 2002) but are not cleaved by MboI (Stancheva et al., 1999). Thus, hemi-methylated

344 plasmids are not amplified by PCR, resulting in a possible underestimation of the replication

345 rate. To be detected, replication of plasmids had to be sufficient for detection by real-time

346 PCR assays.

347 This method made it possible to differentiate the replication efficiency of different plasmids.

348 In this study, non-replicative plasmids showed a background level lower than $10 \%$ of the

349 mean replication rate in all the experiments. This background level could be explained by a

350 percentage of input DNA that becomes DpnI-resistant (Takeda et al., 2005). In this study,

351 mean replication rates could only be determined when the replicative plasmids were

352 cotransfected with pcDNA3.1-Rep. There are two possible explanations for this result: (1) the

353 replicative plasmids could not replicate because Rep and/or Rep' proteins were not produced,

354 or (2) the replication rate was too low to be detected because only low quantities of Rep

355 and/or Rep' proteins were produced. The first explanation can be discounted because it was 
shown that the Rep gene and Rep promoter had not mutated and that the Rep gene was indeed transcribed. However, dysfunction may be caused by the low production of Rep and Rep' or down-regulation of the Rep promoter. It has been reported that transcriptional interference with Epstein-Barr virus-derived vectors depends on the thymidine kinase promoter in the episomal vector (Van Craenenbroeck et al., 2003). However, in eukaryotic cells, the Rep promoter could not be perturbed by the presence of the immediate early CMV promoter or the SV40 promoter in the plasmid because pCR4-Orirep did not contain these eukaryotic promoters. Furthermore, the Rep promoter may not be exchanged with another promoter because it is down-regulated by the Rep protein (Mankertz and Hillenbrand, 2002) which limits the toxicity of Rep on cells. This down-regulation may rapidly decrease the production of proteins and also replication.

pCR4-Orirep seemed to replicate more rapidly than pOrirep0.2-GFP, pOrirep1.2-GFP and pOrirep3.2-GFP. The differences between replicative plasmids were (1) the size of the plasmids, with $5.2 \mathrm{~kb}$ for pCR4-Orirep and 7.3 or $7.4 \mathrm{~kb}$ for pOrirep0.2-GFP, pOrirep1.2-GFP and pOrirep3.2-GFP and (2) although pOrirep0.2-GFP, pOrirep1.2-GFP and pOrirep3.2-GFP contained strong eukaryotic promoters, pCR4-Orirep did not. Strong promoter-enhancers such as the CMV immediate-early gene enhancer interfere with the origin of replication of SV40 (Chen et al., 2000) and oversized vectors, such as BKV replicon plasmids, are more subject to recombination events which may lead to defective replication (Van Craenenbroeck et al., 2000a). The present study showed that size had an impact on the replication rate of rollingcircle replicon-based plasmids, since plasmids with a size of around $5.2 \mathrm{~kb}$ replicated at a high rate and plasmids with larger sizes replicated at lower rates. Prokaryotic rolling-circle replicons generate high-molecular-weight DNA during replication in prokaryotic cells when a fragment is inserted into the replicon (Dabert et al., 1992; Gruss and Ehrlich, 1988). It is possible that replication of PCV2 replicon-based plasmids was initiated, but that replication 
381 could not be terminated due to the large plasmid size, thereby affecting the replication rate. In 382 this study, the strong eukaryotic promoters pCMV and pSV40 did not affect the replication 383 rates.

384 In conclusion, the method described in this study made it possible to calculate plasmid 385 replication rates in eukaryotic cells and to compare different rolling-circle replicons. Using 386 this method, the influence of plasmid size, the presence of strong eukaryotic promoters and 387 the location of the OriRep sequence in the plasmid were studied. This method should be 388 useful for rolling-circle or theta replicons, and in particular for studying the regulation of 389 replicon or virus replication. The quantitative real-time PCR assay reported here could also 390 advantageously be used to evaluate the replication potential of replicon-based plasmids

391 developed for vaccine purposes. Unlike gene therapy, the replicon-based plasmids have to

392 replicate rapidly to produce large amounts of the encoded proteins of interest in a short time. 393 


\section{Acknowledgements}

396 This study was partially supported by grants from the European Commission (Epizone

397 Network of Excellence, Contract No. FOODCT-2006-016236). The authors are grateful to

398 Béatrice Grasland, Yannick Blanchard, Anne-Cécile Nignol (AFSSA, Ploufragan, France)

399 and Prof. Iain Morgan (University of Glasgow, UK) for their advice.

400 


\section{References}

402

403

404

405

406

407

408

409

410

411

412

413

414

415

416

417

418

419

420

421

422

423

424

425

426

427

428

429

430

431

432

433

434

435

436

437

438

439

440

441

442

443

444

445

446

Baxter, M.K., McBride, A.A., 2005. An acidic amphipathic helix in the Bovine Papillomavirus E2 protein is critical for DNA replication and interaction with the E1 protein. Virology 332, 78-88.

Blanchard, P., Mahe, D., Cariolet, R., Keranflec'h, A., Baudouard, M.A., Cordioli, P., Albina, E., Jestin, A., 2003. Protection of swine against post-weaning multisystemic wasting syndrome (PMWS) by porcine circovirus type 2 (PCV2) proteins. Vaccine 21, 456575.

Chen, P.H., Tseng, W.B., Chu, Y., Hsu, M.T., 2000. Interference of the simian virus 40 origin of replication by the cytomegalovirus immediate early gene enhancer: evidence for competition of active regulatory chromatin conformation in a single domain. Mol. Cell. Biol. 20, 4062-74.

Dabert, P., Ehrlich, S.D., Gruss, A., 1992. High-molecular-weight linear multimer formation by single-stranded DNA plasmids in Escherichia coli. J. Bacteriol. 174, 173-8.

Faurez, F., Dory, D., Grasland, B., Jestin, A., 2009. Replication of porcine circoviruses. Virol. J. 6,60 .

Fenaux, M., Halbur, P.G., Haqshenas, G., Royer, R., Thomas, P., Nawagitgul, P., Gill, M., Toth, T.E., Meng, X.J., 2002. Cloned genomic DNA of type 2 porcine circovirus is infectious when injected directly into the liver and lymph nodes of pigs: characterization of clinical disease, virus distribution, and pathologic lesions. J. Virol. 76, 541-51.

Gruss, A., Ehrlich, S.D., 1988. Insertion of foreign DNA into plasmids from gram-positive bacteria induces formation of high-molecular-weight plasmid multimers. J. Bacteriol. 170, 1183-90.

Hefferon, K.L., Fan, Y., 2004. Expression of a vaccine protein in a plant cell line using a geminivirus-based replicon system. Vaccine 23, 404-10.

Hoheisel, J.D., 1993. On the activities of Escherichia coli exonuclease III. Anal. Biochem. 209, 238-46.

Jenny, J.Y., 2001. [Beta risk: an unrecognized risk of statistical error]. Rev. Chir. Orthop. Reparatrice Appar. Mot. 87, 170-2.

Kim, Y.D., Park, K.G., Morishita, R., Kaneda, Y., Kim, S.Y., Song, D.K., Kim, H.S., Nam, C.W., Lee, H.C., Lee, K.U., Park, J.Y., Kim, B.W., Kim, J.G., Lee, I.K., 2006. Liverdirected gene therapy of diabetic rats using an HVJ-E vector containing EBV plasmids expressing insulin and GLUT 2 transporter. Gene Ther. 13, 216-24.

Lu, L., Patel, H., Bissler, J.J., 2002. Optimizing DpnI digestion conditions to detect replicated DNA. Biotechniques 33, 316-8.

Mankertz, A., Caliskan, R., Hattermann, K., Hillenbrand, B., Kurzendoerfer, P., Mueller, B., Schmitt, C., Steinfeldt, T., Finsterbusch, T., 2004. Molecular biology of Porcine circovirus: analyses of gene expression and viral replication. Vet. Microbiol. 98, 81-8.

Mankertz, A., Hillenbrand, B., 2002. Analysis of transcription of Porcine circovirus type 1. J. Gen. Virol. 83, 2743-51.

Mankertz, A., Persson, F., Mankertz, J., Blaess, G., Buhk, H.J., 1997. Mapping and characterization of the origin of DNA replication of porcine circovirus. J. Virol. 71, 2562-6. 
Melot, C., 2003. [What does "power of the study" mean? How to compute the power of a study? How to compute the number of subjects needed for a trial?]. Rev. Mal. Respir. 20, 602-3.

Mor, T.S., Moon, Y.S., Palmer, K.E., Mason, H.S., 2003. Geminivirus vectors for high-level expression of foreign proteins in plant cells. Biotechnol. Bioeng. 81, 430-7.

Morgan, I.M., Taylor, E.R., 2005. Detection and quantitation of HPV DNA replication by Southern blotting and real-time PCR. Methods Mol. Med. 119, 349-62.

Ng, T.F., Manire, C., Borrowman, K., Langer, T., Ehrhart, L., Breitbart, M., 2009. Discovery of a novel single-stranded DNA virus from a sea turtle fibropapilloma by using viral metagenomics. J. Virol. 83, 2500-9.

Padidam, M., Beachy, R.N., Fauquet, C.M., 1999. A phage single-stranded DNA (ssDNA) binding protein complements ssDNA accumulation of a geminivirus and interferes with viral movement. J. Virol. 73, 1609-16.

Rogers, S.G., Weiss, B., 1980. Exonuclease III of Escherichia coli K-12, an AP endonuclease. Methods Enzymol. 65, 201-11.

Shibata, M.A., Miwa, Y., Miyashita, M., Morimoto, J., Abe, H., Otsuki, Y., 2005. Electrogene transfer of an Epstein-Barr virus-based plasmid replicon vector containing the diphtheria toxin A gene suppresses mammary carcinoma growth in SCID mice. Cancer Sci. 96, 434-40.

Stancheva, I., Koller, T., Sogo, J.M., 1999. Asymmetry of Dam remethylation on the leading and lagging arms of plasmid replicative intermediates. Embo J. 18, 6542-51.

Steinfeldt, T., Finsterbusch, T., Mankertz, A., 2007. Functional analysis of cis- and transacting replication factors of porcine circovirus type 1. J. Virol. 81, 5696-704.

Takeda, D.Y., Shibata, Y., Parvin, J.D., Dutta, A., 2005. Recruitment of ORC or CDC6 to DNA is sufficient to create an artificial origin of replication in mammalian cells. Genes Dev. 19, 2827-36.

Taylor, E.R., Morgan, I.M., 2003. A novel technique with enhanced detection and quantitation of HPV-16 E1 - and E2-mediated DNA replication. Virology 315, 103-9.

Van Craenenbroeck, K., Vanhoenacker, P., Duchau, H., Haegeman, G., 2000a. Molecular integrity and usefulness of episomal expression vectors derived from BK and EpsteinBarr virus. Gene 253, 293-301.

Van Craenenbroeck, K., Vanhoenacker, P., Haegeman, G., 2000b. Episomal vectors for gene expression in mammalian cells. Eur. J. Biochem. 267, 5665-78.

Van Craenenbroeck, K., Vanhoenacker, P., Roman, I., Haegeman, G., 2003. Orientationdependent gene expression with Epstein-Barr virus-derived vectors. FEBS Lett. 555, 489-94.

Weiss, B., 1976. Endonuclease II of Escherichia coli is exonuclease III. J. Biol. Chem. 251, 1896-901. 
Figure 1a: Representation of replicative and non-replicative plasmids. From left to right: backbones, non-replicative plasmids and replicative plasmids. Light grey arrow: eGFP reporter gene; black arrow with a stem-loop: PCV2 OriRep; dark grey arrow: IE CMV promoter; black arrow: PCR amplicon obtained with oGVB2115 primers (Table 1); white arrow: PCR amplicon obtained with oGVB2117 primers (Table 1).

Figure 1b: Representation of the replication booster used in this study, pcDNA3.1-Rep. The backbone is pcDNA3.1 zeo+.

Figure 2: PCV2 fragment used to render plasmids replicative. The PCV2 genome is represented on the left. It contains ORF1 (in black), ORF2 (in grey) and an origin of replication (stem loop). The OriRep fragment is boxed.

Figure 3: Quantitation of plasmids by real-time PCR-based replication assay. Non-replicative plasmid, pCR4-GFP; replicative plasmid, pCR4-Orirep. Plasmids were cotransfected with pcDNA3.1-Rep. Total plasmids, quantity of plasmids incubated with ExoIII; quantity of nonreplicated plasmids + replicated plasmids, quantity of plasmids incubated with $D p n \mathrm{I}$ and ExoIII plus quantity of plasmids incubated with $M b o$ I and ExoIII. The real-time PCR experiments were carried out twice using nine replicates ; standard error bars are shown.

Figure 4: Detection of Rep and Rep' mRNAs $24 \mathrm{~h}$ post-transfection in a non-replicative plasmid, a replicative plasmid and a plasmid encoding the Rep gene. Lane 1: non-transfected PK15 cells; lane 2: PK15 cells transfected by pcDNA3-GFP; lane 3: PK15 cells transfected by pOrirep0.2-GFP; lane 4: PK15 cells transfected by pcDNA3.1-Rep. Results for $\beta$-actin mRNA, used as a positive control, are shown.

Figure 5: Need for a plasmid which expresses Rep protein at high levels. pCR4-GFP or pCR4-Orirep were cotransfected into PK15 cells with a pcDN3.1-Rep, or they were cotransfected with pcDN3.1-Rep mutated. The replication rates were calculated as described above. The real time-PCR experiments were carried out twice in duplicate and the standard error bars are shown.

Figure 6: Influence of the two primer pairs designed for the quantitative real time-PCR on the determination of the replication rates. The real-time-PCR-based replication assays were tested with two primer pairs and pcDNA3-GFP and pOrirep0.2-GFP were both cotransfected with pcDN3.1-Rep. a) Representation of the primer pairs b) Quantity of plasmids depending on the primers used. c) Mean replication rate for non-replicative and replicative plasmids for each primer pairs. The real time-PCR experiments were carried out twice in duplicate and the standard error bars are given. The Mann-Whitney test was used to compare differences between results.

Figure 7: Influence of the real time-PCR method on the determination of the replication rates. The real-time-PCR-based replication assays were tested with TaqMan probe 2111 or SYBR Green dye. pcDNA3-GFP and pOrirep0.2-GFP, both cotransfected with pcDN3.1-Rep, were used. a) Representation of the two quantitative real-time PCR methods b) Quantity of plasmids after real time-PCR with the TaqMan probe or the SYBR Green dye. c) Mean rate of replication after real time-PCR with the TaqMan probe or the SYBR Green dye. The real-time 
536 PCR experiments were carried out twice in duplicate and the standard error bars are shown.

537 The Mann-Whitney test was used to compare differences between results.

539 Figure 8: Mean replication rates for PCV2 replicons $24 \mathrm{~h}$ post-transfection. Plasmids were 540 cotransfected into PK15 cells with pcDN3.1-Rep. Replication rates were calculated as 541 described in 3.1. The quantitative real-time PCR experiments were carried out twice in 542 duplicate and the standard error bars are shown. 
545 Table 1: Primer and probe sequences for construction of plasmids, for real-time PCR and for 546 reverse transcriptase PCR

547

\begin{tabular}{|c|c|c|c|c|}
\hline neme & function: & sgecificity & frise of amolicon & locouence \\
\hline agvaziog $F$ & cianing & MfOICASTIG & \multirow{2}{*}{$1231 \geqslant b$} & 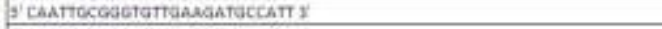 \\
\hline DGVarsoo A & cioning & MLE ACBCG & & 5. ACECGTCCOCACTRAACCCTTAATGA J \\
\hline govazsos $\mathrm{F}$ & tening & Mina AçCGT & \multirow{2}{*}{$1231 p b$ : } & 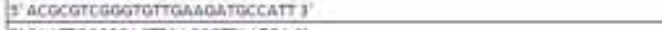 \\
\hline ofiveriol $B$ & clooing & NitoicAATTO & & इ' CAATGCOCCCACTTAACCCCTAATGA. I' \\
\hline Dqvazion $\mathrm{F}$ & ctoning & Drailicactagtg & \multirow{2}{*}{223100} & Y ChCGTAGTGCCACTAACCCCTAATGGATY Y \\
\hline $06 \mathrm{v} 322106 \mathrm{~A}$ & doning & DRZIIICACGTABTG & & 5'CACTACGTGTOTTGAAGATOCCATIITICY' \\
\hline DGV82u1s, F & dianing & Konil GGTacc in the end of ampiollin pese & \multirow{2}{*}{1273,00} & 3 GGTACCGTCTATTRGTTCATCCATAG 3 \\
\hline Dava2:215 A & cloning & Kani GGTACC in the midds of t1 ergin & & 5. EGTACCTCAAICTCTAAATCGGOS Y' \\
\hline DGV & dioning. & 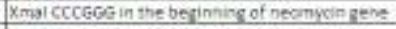 & \multirow{2}{*}{$438 \mathrm{pb}$} & 2 CCCGUGGGCATGATTGAACAAGATG Y \\
\hline Divazi2izh & dianing & 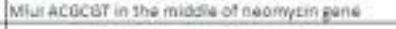 & & F' ACECSTAGTACGTUCTCECTCOAT 3 \\
\hline povazuz F & mutageneis & Tustations $\mathrm{Y}_{m}$ in $\mathrm{F}_{m}$ and $\mathrm{S}_{n} \rightarrow \mathrm{A}_{m}$ & \multirow{2}{*}{1} & 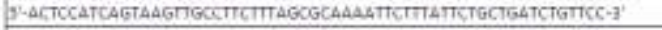 \\
\hline gGVe2L12 月 & mutsiones's & 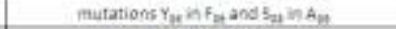 & & 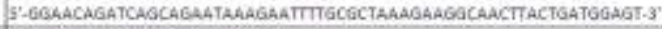 \\
\hline DGVGRIIL $F$ & GFCR mesy & in the GaP rane & \multirow{2}{*}{ 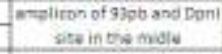 } & 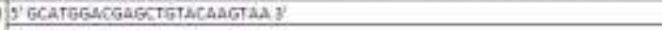 \\
\hline ogve2:i1 $\mathrm{A}$ & QPCF ESSAY & in the bidibone of peDNA3 & & इ' ATCAGCGNACTCTAGCATTAOGS. \\
\hline 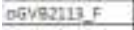 & aPCR nosay & in the reamprin gane & \multirow{2}{*}{$\begin{array}{l}\text { mwoliten of 92pt Opni site } \\
\text { in reverse aremer }\end{array}$} & Y GSTCCTGCCGAGAAAGTATCCY Y \\
\hline Davez:13 $\mathrm{A}$ & qaCh wisar. & in the reamptin forve & & E' THCOCTOUTOSTICGAATOY \\
\hline 9. $\mathrm{F}$ & RTPCRBES & in the bepinning of pes gene & \multirow{2}{*}{$\begin{array}{l}\text { amplican of Alep }=774 \mathrm{pb} \\
\text { amplicen ef hep }=391 \mathrm{pb}\end{array}$} & 5. GIGGGTGTTCACTCTGAATAA, \\
\hline gavazsia $n$ & at posk ney & Mter the send ef introo of thap gen & & 3. AQAGCTICTACAGCTODGACA I' \\
\hline probe 2111 & arobe opCh assar & FAM-SGGB & 1 & УССTCGAGCATGCATCTA \\
\hline Aactine fanwart & AT PCE factines & 1 & \multirow{2}{*}{ eape } & 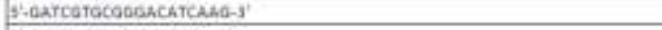 \\
\hline jactine reverse & AT PCB pactine & 1 & & S. GGCCATCTCCTECTCGAAY Y \\
\hline
\end{tabular}




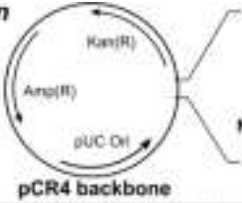

pCR4 backbone

Constructs for example of replication rate

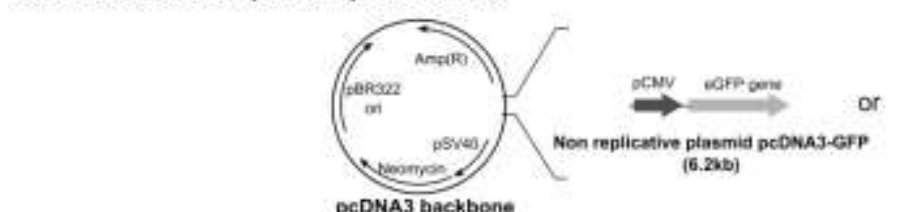

Constructs for the study of the influence of the promoter on replication

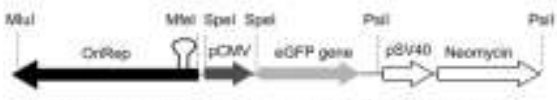

Replicative plasmid pOrirep0.2-GFP backbone

Constructs for the study of the influence of the size on replication

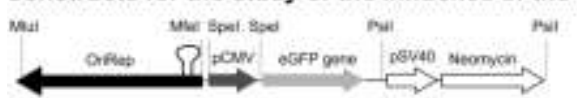

Replicative plasmid pOrirep0.2-GFP backbone

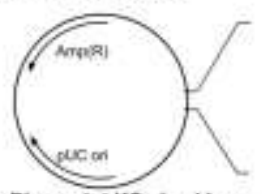

Figure 1a

pBluescript KS+ backbone

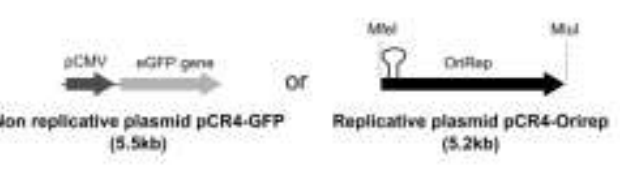

(s.2kb)
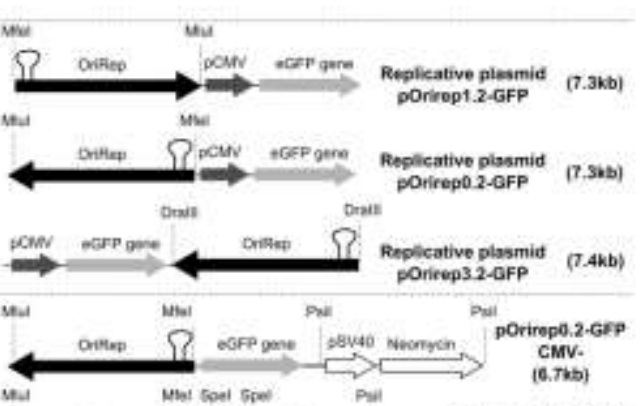

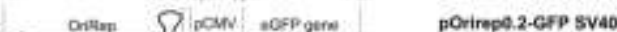

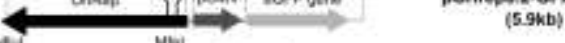

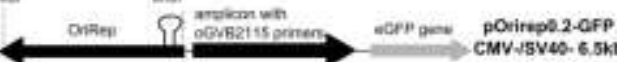
(6.5kb)

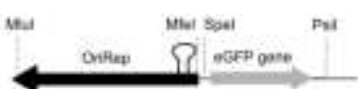

POrirepo. 2-GFP MV 19 40. 5.2kb (5.2kb)

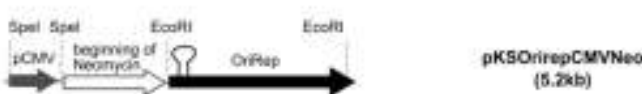

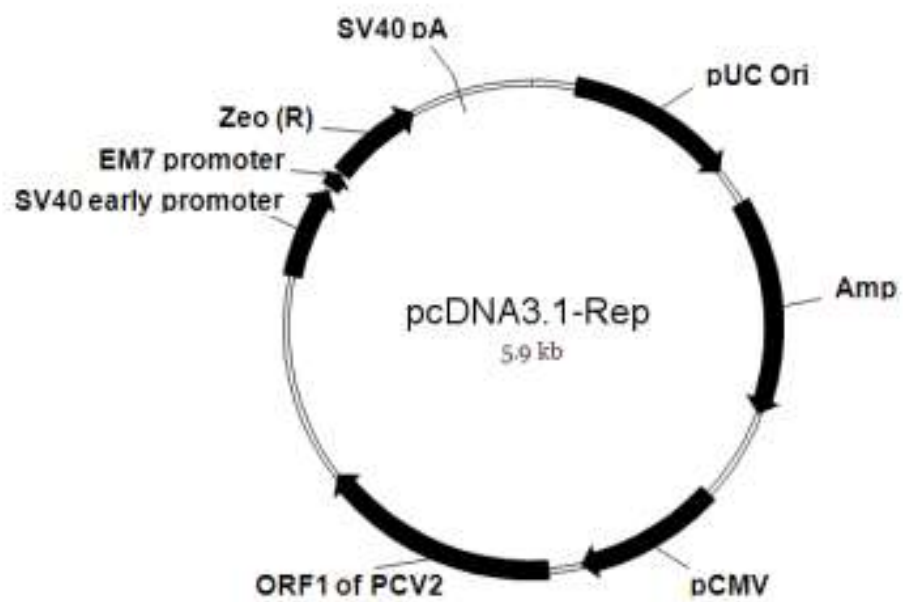

Figure 1b 
560

561

562

563

564

565

566

567

568

569

570

571

Well 1 Well 2 Well 3 Well 4 MW

Figure 2

Figure 3

$\beta$-actin

Figure 4
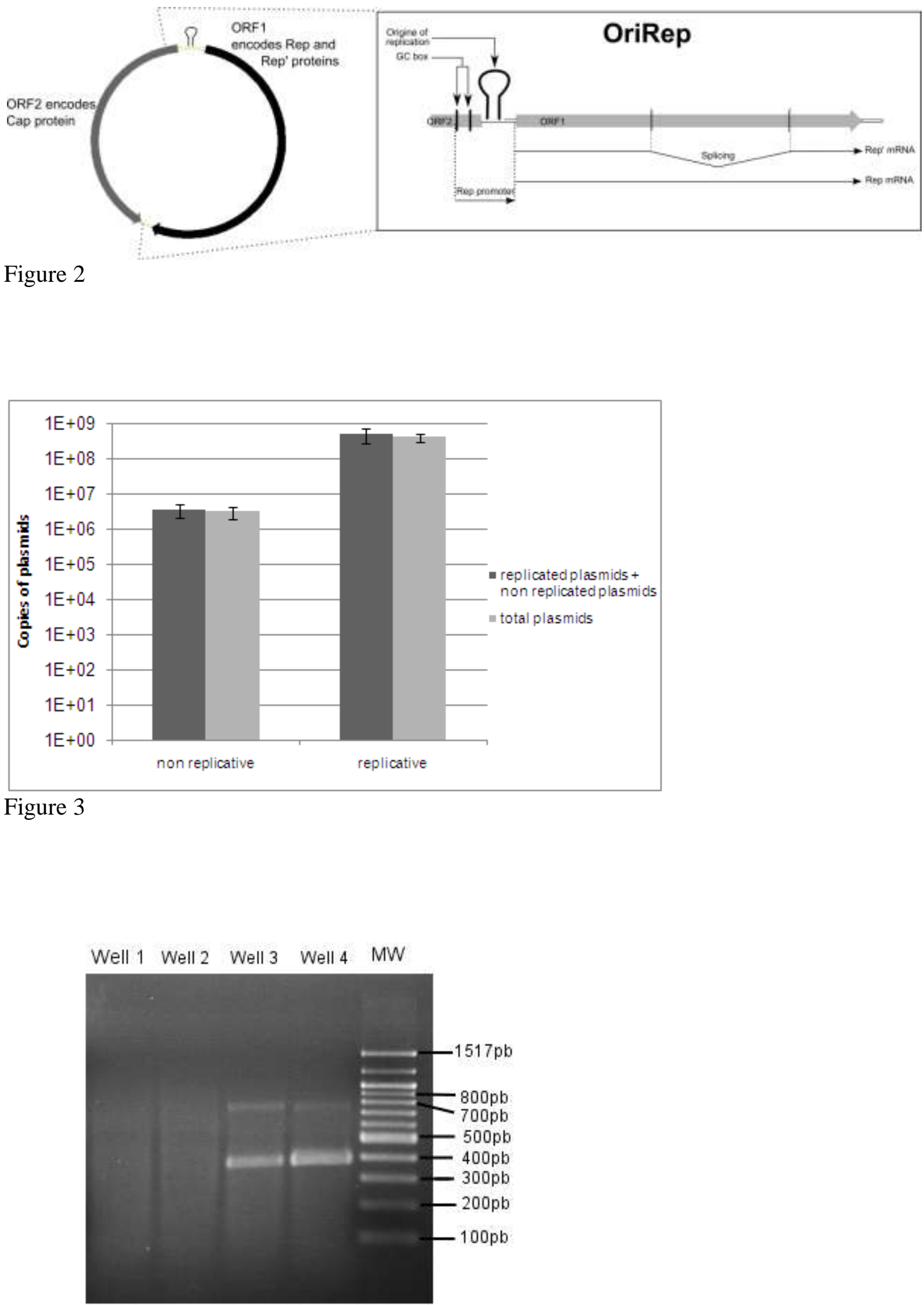

Page 25 


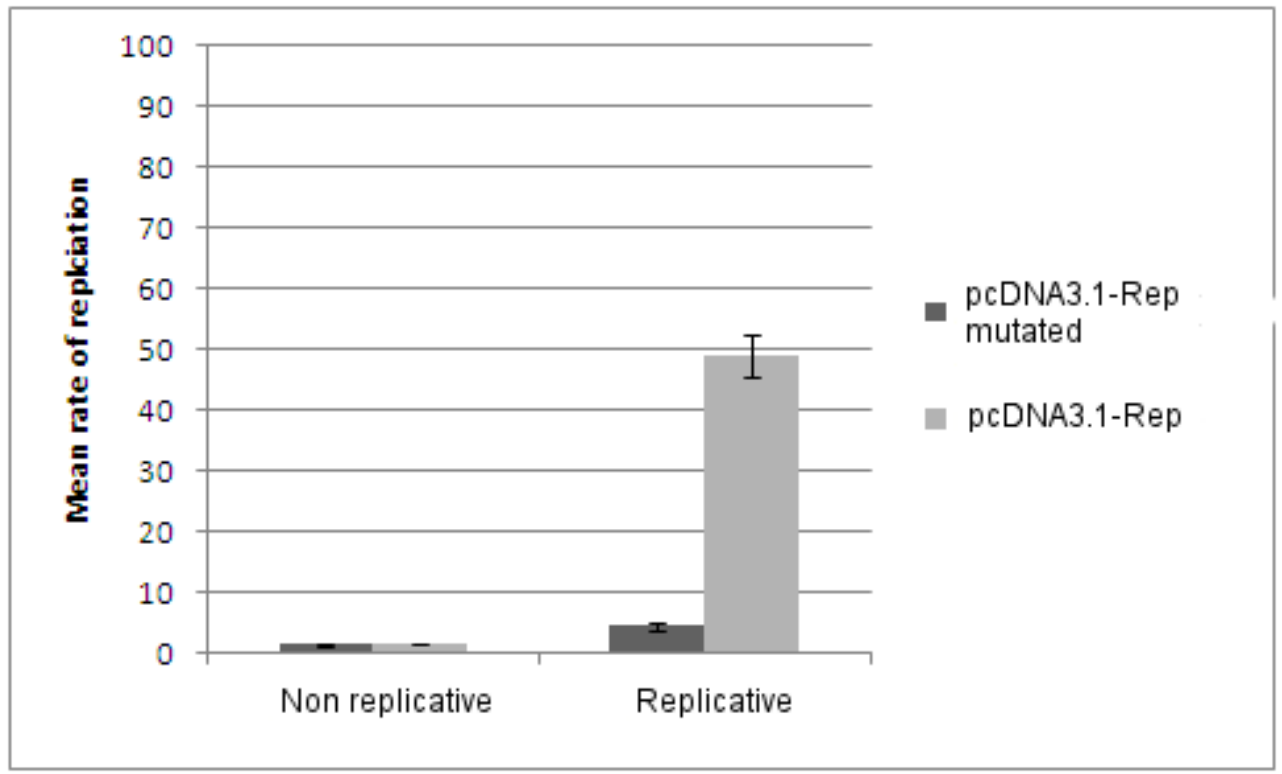

577

578

579

580

581

Figure 5
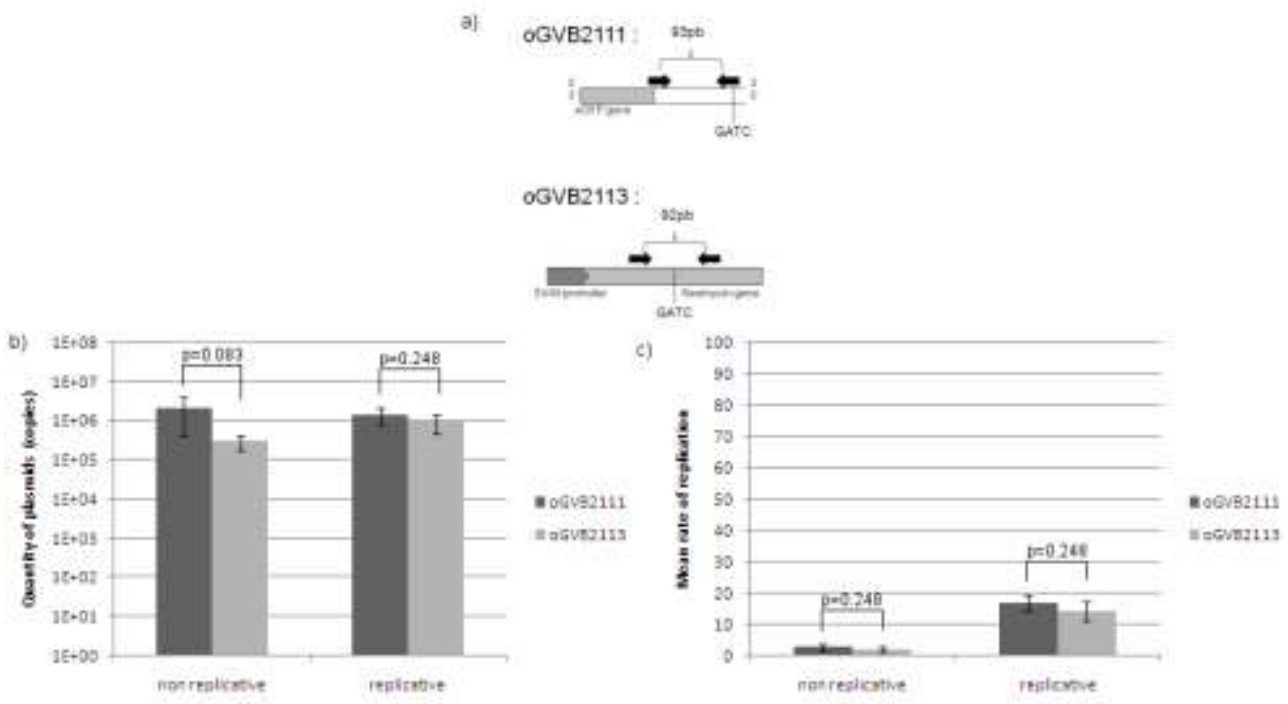

582

583

Figure 6

584 
585

586

587

588

589

590

591

592

593

594

595

596

a) oGVB2111 + TaqMan probe

b)

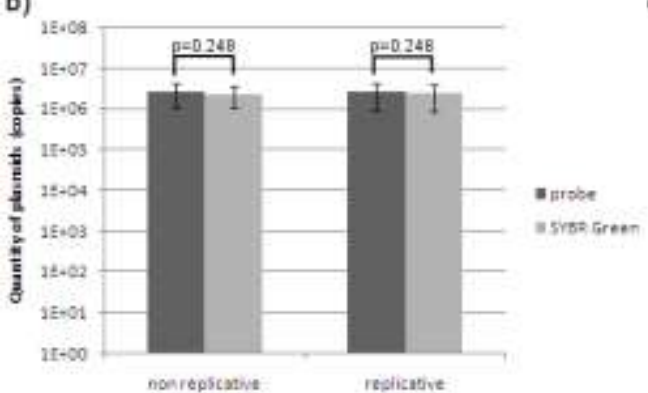

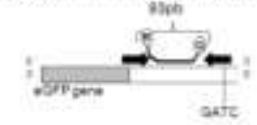

oGVB2111 + SYBR Green mix

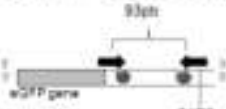

c)

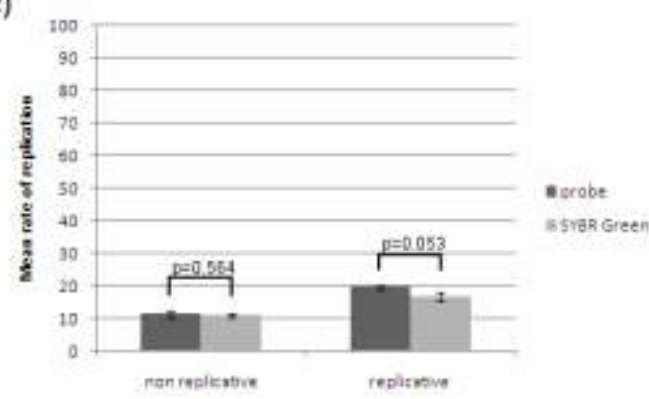

Figure 7

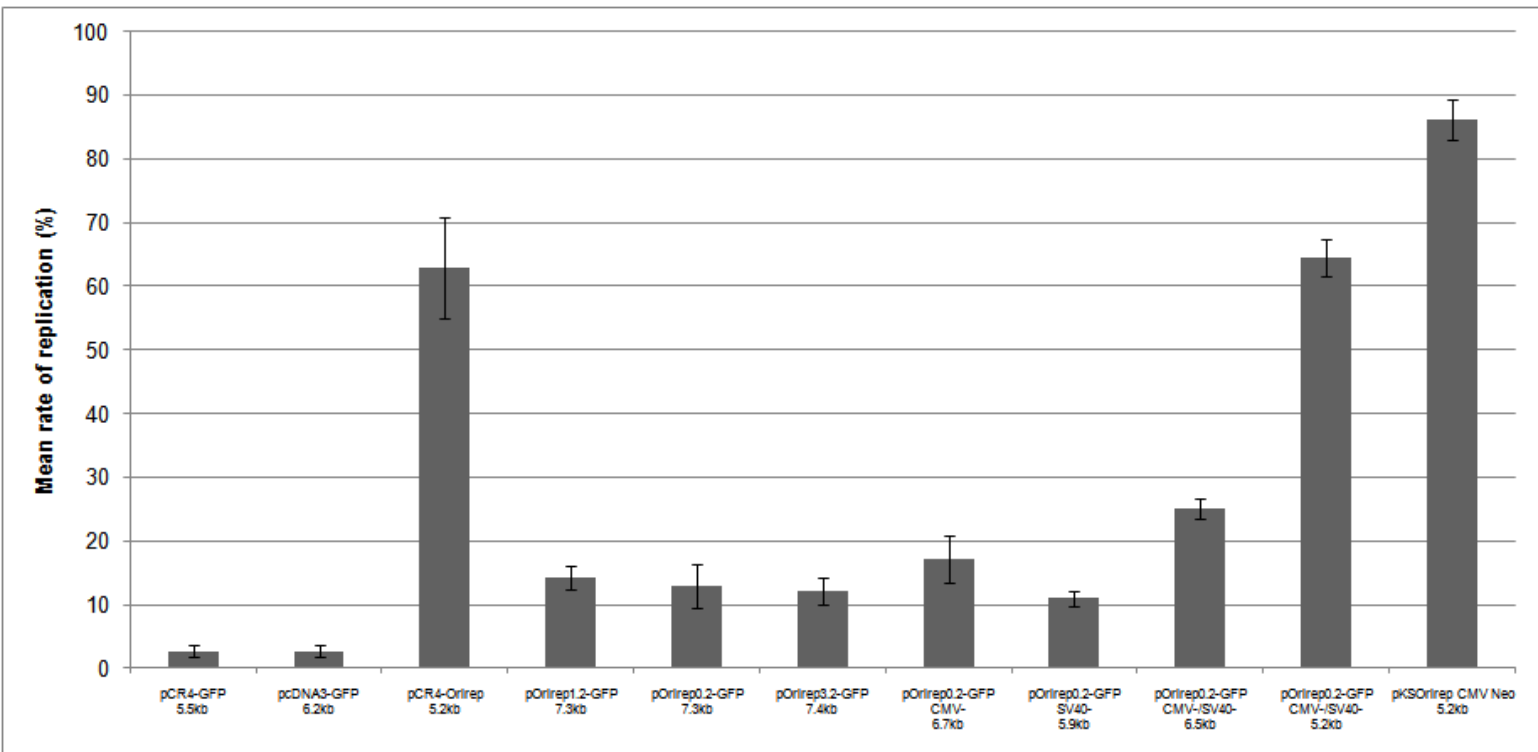

Figure 8

Page 27 